\title{
Assessment of in vivo genotoxicity of citrated- coated silver nanoparticles via transcriptomic analysis of rabbit liver tissue
}

This article was published in the following Dove Press journal: International Journal of Nanomedicine

\author{
Yeo Jin Kim ${ }^{1,2}$ \\ Md Mujibur Rahman' \\ Sang Min Lee ${ }^{2}$ \\ Jung Min $\mathrm{Kim}^{3}$ \\ Kwangsik Park ${ }^{4}$ \\ Joo-Hyon Kang ${ }^{5}$ \\ Young Rok Seo ${ }^{1,2}$ \\ 'Institute of Environmental Medicine \\ for Green Chemistry, Dongguk \\ University Biomedi Campus, \\ Ilsandong-gu, Goyang-si, Republic of \\ Korea; ${ }^{2}$ Department of Life Science, \\ Dongguk University Biomedi Campus, \\ Ilsandong-gu, Goyang-si, Republic \\ of Korea; ${ }^{3}$ Genoplan Korea, Inc., \\ Seocho-gu, Seoul, Republic of Korea; \\ ${ }^{4}$ College of Pharmacy, Dongduk \\ Women's University, Seongbuk-gu, \\ Seoul, Republic of Korea; ${ }^{5}$ Department \\ of Civil \& Environmental Engineering, \\ Dongguk University, Jung-gu, Seoul, \\ Republic of Korea
}

Correspondence: Young Rok Seo Department of Life Science, Dongguk University Biomedi Campus,

32 Dongguk-ro, Ilsandong-gu, Goyang-si, Gyeonggi-do 10326, Republic of Korea

Tel +823I 9615172

Email seoyr@dongguk.edu
Background: Silver nanoparticles (AgNPs) are widely used in industrial and household applications, arousing concern regarding their safety in humans. The risks posed by stabilizercoated AgNPs continue to be unclear, and assessing their toxicity is for an understanding of the safety issues involved in their use in various applications.

Purpose: We aimed to investigated the long-term toxicity of citrate-coated silver nanoparticles (cAgNPs) in liver tissue using several toxicity tests and transcriptomic analysis at 7 and 28 days after a single intravenous injection into rabbit ear veins $(n=4)$.

Materials and methods: The cAgNPs used in this study were in the form of a $20 \%(\mathrm{w} / \mathrm{v})$ aqueous solution, and their size was $7.9 \pm 0.95 \mathrm{~nm}$, measured using transmission electron microscopy. The animal experiments were performed based on the principles of good laboratory practice.

Results: Our results showed that the structure and function of liver tissue were disrupted due to a single exposure to $\mathrm{c} A \mathrm{gNPs}$. In addition, in vivo comet assay showed unrepaired genotoxicity in liver tissue until 4 weeks after a single injection, suggesting a potential carcinogenic effect of cAgNPs. In our transcriptomic analysis, a total of 244 genes were found to have differential expression at 28 days after a single cAgNP injection. Carefully curated pathway analysis of these genes using Pathway Studio and Ingenuity Pathway Analysis tools revealed major molecular networks responding to cAgNP exposure and indicated a high correlation of the genes with inflammation, hepatotoxicity, and cancer. Molecular validation suggested potential biomarkers for assessing the toxicity of accumulated cAgNPs.

Conclusion: Our investigation highlights the risk associated with a single cAgNP exposure with unrepaired damage persisting for at least a month.

Keywords: nanotoxicity, liver toxicity, prolonged tissue damage, differentially expressed genes, molecular pathway analysis

\section{Introduction}

Engineered nanoparticles (NPs) have unique physiochemical properties. Silver NPs (AgNPs) are frequently used in the production of a variety of commercial products including creams and ointments, cosmetics, and paint. ${ }^{1-3}$ The antimicrobial nature of AgNPs has been exploited in different industries in bactericidal and fungicidal coatings, and in medical devices, water purification, and air quality management. ${ }^{4,5}$ All of these applications have increased the environmental exposure of AgNPs, which has raised concern regarding potential toxicity hazards to human health. ${ }^{1,6}$ Indeed, AgNP toxicity on growth and reproduction has been described in invertebrates such as the waterflea ${ }^{7}$ and vertebrates such as fish. ${ }^{8}$ Because NPs are easily agglomerated in the molecular environment, AgNPs are commonly used as coatings to stabilize nanosized objects. Citrate is the most common 
stabilizer in the synthesis process, and it imparts a negative surface charge. ${ }^{9,10}$ Recent studies have reported the effects of stabilizer-coated AgNPs in vitro, indicating cyto- and genotoxicity of such coated AgNPs. ${ }^{11-13}$ Recent studies have also reported the potential toxicity of AgNPs to humans; ${ }^{3,14}$ however, the mechanisms involved have not yet been clearly identified.

AgNPs that are absorbed in mammals may be circulated and distributed to various soft tissues including liver, spleen, blood, kidney, and brain. ${ }^{3,15,16}$ Liver has been proposed as a major target organ for the evaluation of AgNP toxicity in rodents. ${ }^{17,18}$ A significant quantity of AgNPs is detected in the liver of rats following a 90-day oral administration. ${ }^{17}$ In addition, several toxicological studies have reported that AgNPs might cause hepatotoxicity due to the generation of reactive oxygen species (ROS). ${ }^{19-21}$ However, mechanisms of AgNP toxicity in different tissues are still unclear. Thus, the usage of AgNPs in various applications remains widespread, potentially threatening human health.

Toxicogenomic approaches have been used in recent assessment of AgNP toxicity. ${ }^{22,23}$ Toxicogenomics has been emerged in toxicological research, following the development of genomics technology. It is also used in bioinformatics to better understand the molecular mechanisms of toxicants in biosystems. ${ }^{24,25}$ Microarray technology permits the examination of the transcriptome, which potentially includes the global genomic profile of cellular responses at the mRNA level. The majority of microarray analyses to date have focused on disease-related mechanisms. ${ }^{26}$ Recently, a meaningful interpretation of transcriptomic data has been emphasized to provide a comprehensive view of biological responses to chemicals. ${ }^{24}$ To gain insights of interest from complex and dynamic biological systems, a thorough review of published reports and integration of information is necessary. Currently, various companies and researchers have developed pathway analysis software which functions via computational text-mining and analysis of vast amounts of literature. Toxicogenomics enables the prediction of mode of action and deeper knowledge of mechanism of action, even when little is known regarding the compounds of interest. ${ }^{25}$

Only a few studies have addressed alterations in the transcriptome due to in vivo AgNP exposure. ${ }^{22,27}$ In the present study, we investigated the in vivo toxicity of stabilized AgNps in a rabbit model following the organization for economic cooperation and development (OECD) principles of good laboratory practice (GLP). Rabbit is one of the most commonly used animal models for standardized developmental toxicity testing of pharmaceuticals and chemicals including that of the human teratogen thalidomide. ${ }^{28}$ We used citratecoated, stabilized AgNPs (cAgNps) in the present study.
In our previous study, we investigated time-dependent kinetics of $\mathrm{cAgNPs}$ after a single intravenous injection and found that liver was the main site for the accumulation and pigmentation of cAgNPs with harmful effects was observed over a prolonged period. ${ }^{29}$ Hepatotoxicity was one of the effects observed, which was evaluated by detecting transcriptional alterations, cytotoxicity, generation of oxidative stress, and genotoxicity. Two different doses of cAgNPs were intravenously injected into rabbits, and toxicology analyses were conducted at different time points. The purpose of the present study was to assess unrepaired damage in rabbit liver tissue in terms of genotoxicity, oxidative stress, and differential gene expression, after a single injection of cAgNPs.

\section{Materials and methods}

\section{Chemicals}

Purified (99.98\% pure) and colloidal AgNPs coated with citrate (cAgNPs; SARPU $200 \mathrm{KW}$ ) were obtained from ABC NANOTECH (Daejeon, Republic of Korea). We have previously described their characteristics. ${ }^{29}$ The cAgNPs were provided as a $20 \%(\mathrm{w} / \mathrm{v})$ aqueous stock solution. Particle size was $7.9 \pm 0.95 \mathrm{~nm}$ as determined using transmission electron microscopy. The average $\pm \mathrm{SD}$ zeta potential of $10 \mathrm{ppm}$ aqueous cAgNP suspensions was $-17.55 \pm 4.16 \mathrm{mV}$. The suspension of $\mathrm{cAgNPs}$ for intravenous injection was prepared by diluting the stock $\mathrm{cAgNPs}$ with isotonic 5\% glucose solution to final concentrations of 0.25 and $2.5 \mathrm{mg} / \mathrm{mL}$, which corresponded to $0.5 \mathrm{mg} / \mathrm{kg}$ (low dose) and $5 \mathrm{mg} / \mathrm{kg}$ (high dose) when injected into rabbits at $2 \mathrm{~mL} / \mathrm{kg}$ body weight.

\section{Animals and treatment}

The animals were handled following the principles of GLP. Specific pathogen-free New Zealand White rabbits were purchased from Samtako Bio Korea Company (Osan, Gyeonggi-do, Republic of Korea). They were allowed to adapt to the animal room conditions for 1 week prior to the initiation of the study. Further details have been provided previously. ${ }^{29}$ Briefly, four male rabbits received a single injection of the low- or high-dose cAgNps through an ear vein. The doses were chosen per preliminary experiments based on OECD test guideline 417. No rabbit died and no significant adverse effects that might affect the kinetics study were observed during the study period. Following the single injection of cAgNPs, liver tissues of rabbits were isolated for toxicity tests and microarray analysis at 7 and 28 days after the injection.

\section{Animal ethics}

All animal procedures were reviewed and approved by the animal ethics committee of the Institutional Animal Care 
and Use Committee of ChemOn Inc., a contract research organization for non-clinical area (Reference number: 11-B020; Gyeonggi-do, Republic of Korea). Animal care procedures were performed in accordance with the principles outlined in the "Guide for the Care and Use of Laboratory Animals" issued by the Animal Care and Committee of National Veterinary Research and Quarantine Service and with the guidelines of the Institutional Animal Care and Use Committee of ChemOn Inc.

\section{ALP and lactate dehydrogenase $(\mathrm{LDH})$ assays}

The ALP assay was performed using a tartrate-resistant acid phosphatase and ALP Assay kit (cat. no MK301; Takara Bio, Shiga, Japan). The LDH assay kit was purchased from Sigma-Aldrich Co. (cat. no tox7; St Louis, MO, USA). Liver tissues and lysis solution (cat. no L2152; Sigma-Aldrich Co.) were added at a 1:10 ratio. The tissues were homogenized and incubated for 45 minutes.

\section{TUNEL assay}

The TUNEL assay was performed using a DeadEnd ${ }^{\mathrm{TM}}$ Fluorometric TUNEL System kit (cat. no G3250; Promega Corporation, Fitchburg, WI, USA). After removing the specimens and rehydrating the paraffin, the slides were washed in $0.85 \%$ $\mathrm{NaCl}$ in PBS for 5 minutes. The slides were fixed with $4 \%$ formaldehyde in PBS followed by washing with PBS. A $100 \mu \mathrm{L}$ aliquot of a $20 \mu \mathrm{g} / \mathrm{mL}$ Proteinase $\mathrm{K}$ solution was added and incubated at room temperature for 8-10 minutes. Then, the slides were sequentially immersed in PBS for 5 minutes, $4 \%$ formaldehyde in PBS for 5 minutes, and PBS for 5 minutes. A $100 \mu \mathrm{L}$ aliquot of equilibration buffer was added and incubated at room temperature for 5-10 minutes. A $50 \mu \mathrm{L}$ aliquot of the terminal deoxynucleotidyl transferase reaction mix was added to the tissue and incubated for 60 minutes at $37^{\circ} \mathrm{C}$ in a humidified chamber. This and the subsequent steps were done in the dark. The coverslips were removed, and the slides were immersed in $2 \times$ saline-sodium citrate buffer for 15 minutes followed by three washes of 5 minutes each in PBS. Specimens were mounted and visualized with Vectashield ${ }^{\circledR}$ (Vector Laboratories, Burlingame, CA, USA) and DAPI. Localized green fluorescence of the apoptotic tissue was observed using confocal fluorescence microscopy. DAPI-stained nuclei were blue.

\section{Malondialdehyde (MDA) and 4-hydroxynonenal (4-HNE) ELISA}

The MDA assay was performed by using an OxiSelect ${ }^{\mathrm{TM}}$ MDA Adduct ELISA kit (cat. no STA-332-5; Cell Biolabs,
Inc., San Diego, CA, USA). The HNE assay was done using an OxiSelect ${ }^{\mathrm{TM}} \mathrm{HNE}$ Adduct ELISA kit (cat. no STA-338-5; Cell Biolabs, Inc.). BSA standards or protein samples $(10 \mu \mathrm{g} / \mathrm{mL})$ were adsorbed in wells of a 96-well plate for 2 hours at $37^{\circ} \mathrm{C}$. The MDA- or HNE-protein adducts present in the sample or standard were probed with anti-MDA or anti-HNE antibody, followed by horseradish peroxidaseconjugated secondary antibody. Content of each protein adduct in the unknown sample was determined by comparing the OD values with those of a standard curve prepared using predetermined target protein-BSA standards.

\section{Comet assay}

The alkaline $(\mathrm{pH}>13)$ comet assay for quantifying DNA lesions was conducted following the protocol used in the international validation of the in vivo rodent alkaline comet assay for detecting genotoxic carcinogens. Rabbit livers were collected and minced using scissors in cold mincing buffer. The mincing buffer consisted of $\mathrm{Mg}^{++}$and $\mathrm{Ca}^{++}$free Hank's Balanced Salt Solution (Thermo Fisher Scientific, Waltham, MA, USA) with $20 \mathrm{mM} \mathrm{Na}$ EDTA (Sigma-Aldrich Co.) and $10 \% \mathrm{v} / \mathrm{v}$ dimethyl-sulfoxide (Sigma-Aldrich Co.). The comet assay protocol has been previously described. ${ }^{30}$

\section{Microarray}

After sacrificing the rabbits, liver tissue was obtained and preserved in liquid nitrogen. RNA was extracted immediately to avoid any deterioration and was isolated using an RNeasy Mini kit 250 (cat. no 74106; Qiagen NV, Venlo, the Netherlands) following the manufacturer's recommendations. RNA quality was determined using the Bioanalyzer Nano Chip 2100 (Agilent Technologies, Santa Clara, CA, USA). Total RNA ( $1 \mu \mathrm{g})$ was used for amplification and labeling using the Low Input Quick Amp Labeling Kit (Agilent Technologies) as described by the manufacturer. Yields of cRNA and the dye-incorporation rate were measured with an ND-1000 spectrophotometer (NanoDrop Technologies, Winooski, VT, USA). The hybridization procedure was performed per the Two-Color Microarray-Based Gene Expression Analysis protocol using a Gene Expression Hybridization Kit (Agilent Technologies). Briefly, 825 ng of the corresponding Cy3- and Cy5-labeled cRNA was combined and hybridized overnight in a $65^{\circ} \mathrm{C}$ hybridization chamber with a Rabbit Gene Expression Microarray 4×44K (ID G2519F-020908; Agilent Technologies). The array was scanned using a DNA microArray scanner (Agilent Technologies), and probe signals were quantified using Feature Extraction software (version 10.2.1.3; Agilent 
Technologies). Normalized data were analyzed using platform v1.16.4376 (Subio Inc., Kagoshima, Japan).

\section{Functional interaction and gene pathway analysis}

Pathway Studio web-based edition 11.0.6 software (Ariadne Genomics, Rockville, MD, USA) and Ingenuity Pathway Analysis (Ingenuity Systems; Qiagen NV) were used to investigate the functional interactions and possible pathways among the genes identified from the microarray experiment. These software help in assessing the biological significance of genes by analyzing their interactions with related cell processes and diseases. Pathway Studio uses an inbuilt RESNET database of molecular interactions based on textmining and processing of scientific abstracts in PubMed. ${ }^{31}$ It also utilizes all the existing pathway database and identifies connections among all proteins in a new specific pathway. Ingenuity Pathway Analysis is based on the comprehensive, manually curated content of the Ingenuity Knowledge Base. ${ }^{32}$ It helps predict upstream regulators and downstream effects in biological and disease processes.

\section{Reverse transcription PCR (RT-PCR) and quantitative real-time PCR}

Conventional RT-PCR for the rabbit genes identified from the microarray experiments was performed. Quantitative real-time PCR was performed using SYBR premix Ex Taq (Takara) on an Applied Biosystems 7500 Real-Time PCR system (Thermo Fisher Scientific). The PCR primers were synthesized by Integrated DNA technology (Coralville, IA, USA). All samples were run in duplicate, and the mRNA levels were normalized to those of glyceraldehyde-3-phosphate dehydrogenase.

\section{Results}

\section{Damage to liver function and tissue structure due to $\mathrm{cAgNPs}$}

To evaluate liver toxicity of cAgNPs, we initially examined the level of common liver function markers, ALP and LDH. Increased ALP, which is an enzyme related to bile ducts, is associated with drug-induced cholestasis and liver damage in humans. ${ }^{33}$ The ALP level increased in a dose-dependent manner and decreased in a time-dependent manner in response to cAgNP treatment (Figure 1A). LDH catalyzes the interconversion of lactate and pyruvate as a key step in aerobic glycolysis. ${ }^{34}$ The level of LDH showed a pattern of expression that was similar to ALP (Figure 1B). In addition, the TUNEL assay data showed increased apoptosis in the cAgNP-exposed rabbit liver tissue in a dose-dependent manner, with a subsequent time-dependent decline (Figure $1 \mathrm{C}$ and D). Apoptosis increased significantly with the high dose $(5 \mathrm{mg} / \mathrm{kg})$ cAgNP treatment compared to the low dose $(0.5 \mathrm{mg} / \mathrm{kg})$ treatment at day 7 , with a decline at day 28 in both the groups. The results indicated that the high dose of cAgNPs was more toxic and that tissue damage persisted in the rabbit liver tissue.

\section{Oxidative stress and DNA damage induced in cAgNP-treated rabbit liver tissue}

Lipid peroxidation is a well-defined mechanism of response to cellular damage. Peroxidation is an indicator of unstable oxidative stress that involves decomposition to form more complex and reactive compounds such as MDA and 4-HNE. ${ }^{35} \mathrm{MDA}$ and HNE expression in the rabbit liver was higher in the $5 \mathrm{mg} / \mathrm{kg}$ group than in the $0.5 \mathrm{mg} / \mathrm{kg}$ group at day 7 and subsequently decreased with time (Figure 2A and B). To assess the genotoxicity of cAgNPs in liver tissue, the in vivo alkaline comet assay was performed with dose-dependent or time-dependent exposure. Assessment of in vivo genotoxic potency is a major step to predict in vivo carcinogenicity. DNA strand breaks in liver tissue dosedependently increased after cAgNP treatment; interestingly, the DNA damage had slightly declined in the high-dose treated group after 28 days compared to the damage at day 7 (Figure 2C and D). These results demonstrated dose- and time-dependent changes in oxidative stress and DNA damage after a single injection of cAgNPs.

\section{Global gene expression profiling under cAgNP exposure in liver tissue}

Microarrays are widely used for transcriptome analysis. To investigate vestigial damages in liver tissue, microarray analysis using GeneString was done to identify differentially expressed genes 28 days after exposure to $5 \mathrm{mg} / \mathrm{kg}$ cAgNPs. Genes showing a change of 1.5 -fold with $P<0.05$ were selected for further analysis to identify potential biomarkers of cAgNP exposure. Overall, the expression of 244 genes was altered with 134 being upregulated and 110 being downregulated. Biological interactions between the genes with significantly altered expression were analyzed using Pathway Studio (Elsevier, Amsterdam, the Netherlands) and Ingenuity Pathway Analysis (Qiagen NV).

Pathway Studio is based on performing text-mining from published reports. By using Pathway Studio, direct interactions among the differentially expressed genes were identified, and functional relations with the genes were analyzed in terms of cellular processes (Figure 3A) and diseases 


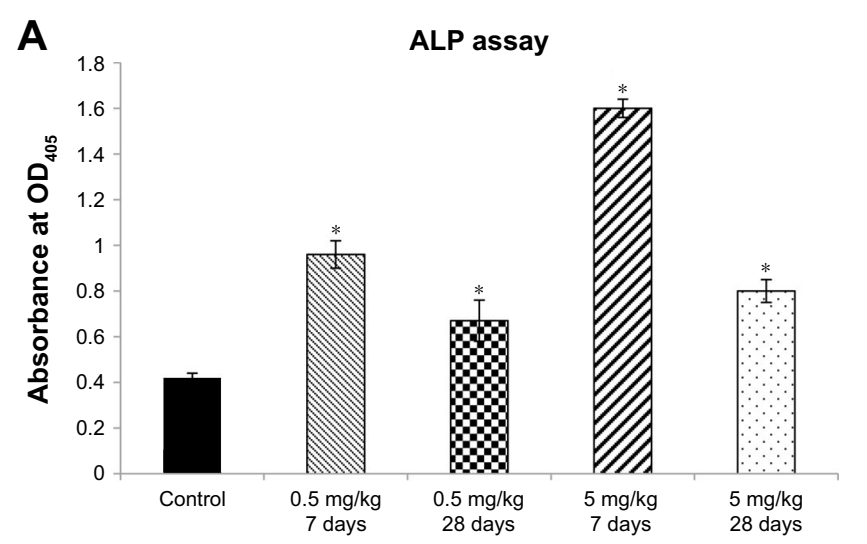

C
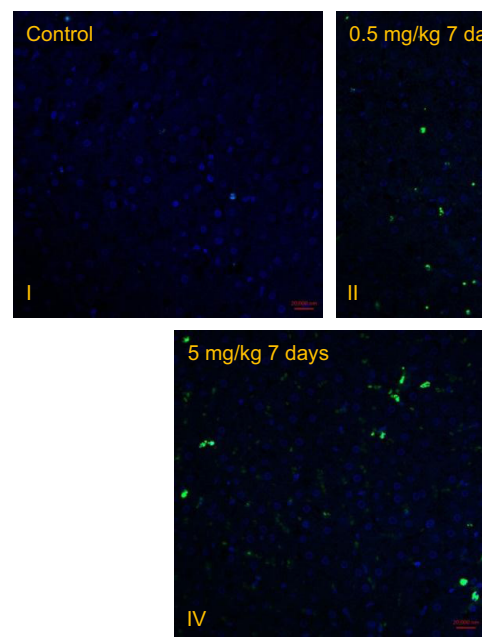

$5 \mathrm{mg} / \mathrm{kg} 28$ days

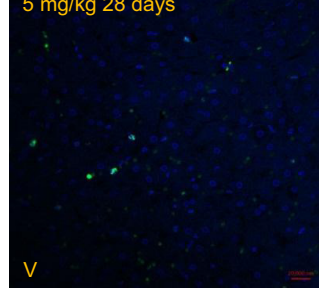

B

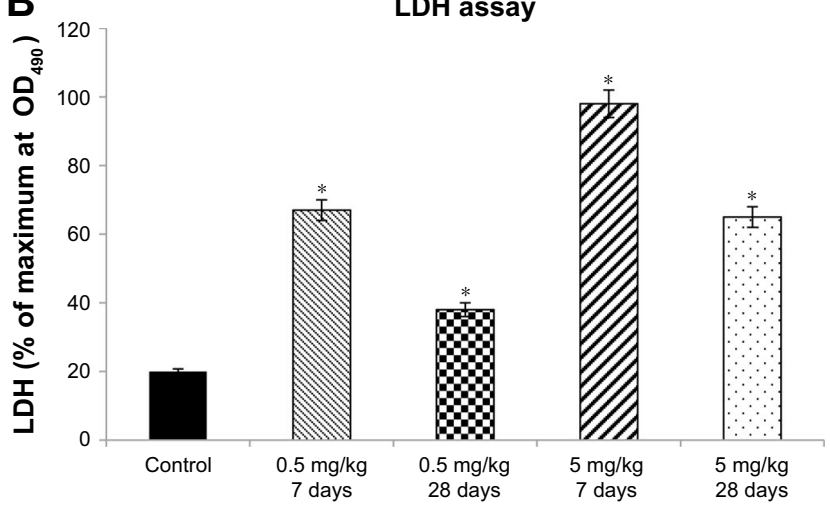

D
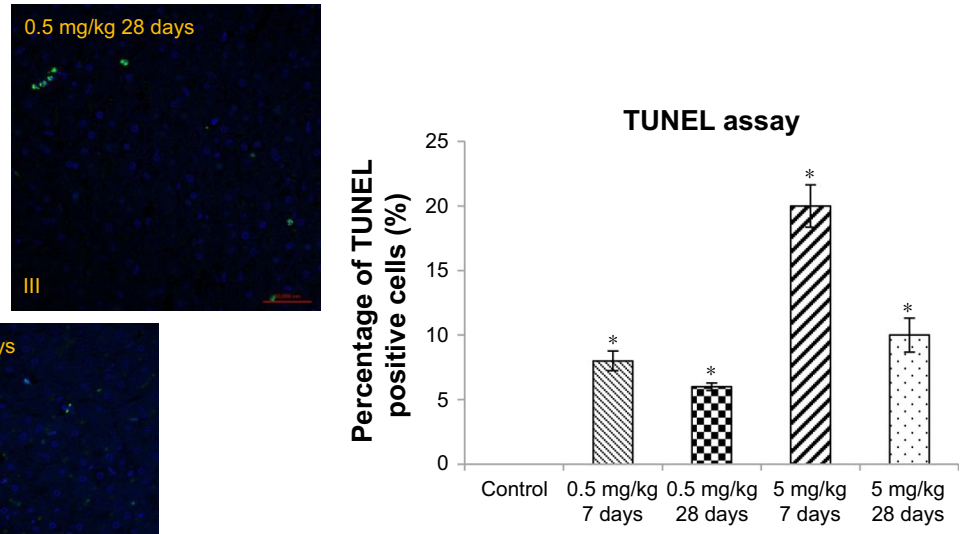

Figure I Liver tissue damage caused by cAgNP treatment.

Notes: ALP and LDH levels were used as enzymatic indication of cAgNP liver toxicity (A and $\mathbf{B}$, respectively). The high dose (5 mg/kg) resulted in greater levels of both the enzymes than the low dose $(0.5 \mathrm{mg} / \mathrm{kg})$, and the enzyme levels decreased but persisted till the end of the experiment at both the treatment doses. (C and $\mathbf{D})$ show results of the TUNEL assay and statistical analysis of the apoptosis-positive cells scoring in cAgNP-treated liver tissue, respectively, where the high dose (5 mg/kg) resulted in more TUNEL-positive cells than the low dose $(0.5 \mathrm{mg} / \mathrm{kg})$, and TUNEL-positive cells decreased at the end. The asterisk indicates a significant difference compared to the control group ( $P$-value $<0.05)$.

Abbreviations: $\mathrm{cAgNP}$, citrate-coated silver nanoparticle; LDH, lactate dehydrogenase.

(Figure 3B). Up- and downregulated genes were highlighted in red and blue, respectively. In the network analysis, ROS generation, cellular stress, and oxidative stress among the cellular process-related pathways were highly connected with our input genes. In disease-related pathways, inflammation and hepatotoxicity were mostly connected with the differentially expressed genes. Among the genes, TP53, CDK1, SERPINE1, AURKA, and VWF had several connections with other elements. The identified cell processes and diseases and the significantly associated genes were considered potential key factors involved in cAgNP toxicity.

Ingenuity Pathway Analysis explores gene expression data sets through algorithms integrating literature-supported relationships between a variety of contexts in the Ingenuity Knowledge Base. ${ }^{32}$ Differentially expressed genes were analyzed 28 days after cAgNP treatment, and the topranked network among the genes and association with liver proliferation, liver necrosis, increase of liver hyperplasia, and $\mathrm{p} 53$ signaling were identified (Figure 4). The upstream regulators $A H R, J U N$, and PPARA were predicted by this tool, indicating their relevance to liver toxicity and their predicted role in gene modulators affected by cAgNPs, even though their expression levels were not significantly altered. The analysis found that CDK1, SERPINE1, TP53, and INSIG2 were modulated by at least two of the predicted upstream regulators and were associated with hepatic system diseaserelated genes. These findings suggest potential biomarkers of cAgNP toxicity after 28 days of treatment.

\section{Identification of biological networks in response to $\mathrm{cAgNP}$ exposure}

To obtain insight into more specific mechanisms of cAgNP toxicity, the pathways were analyzed in greater depth using Pathway Studio considering the number of references and 
A

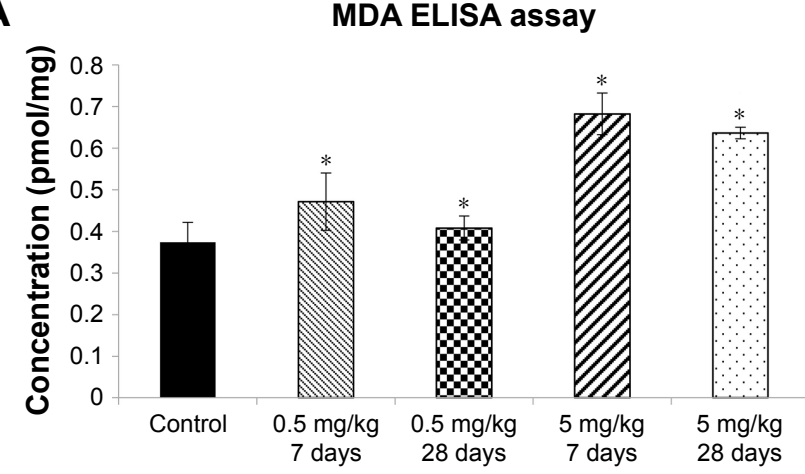

C

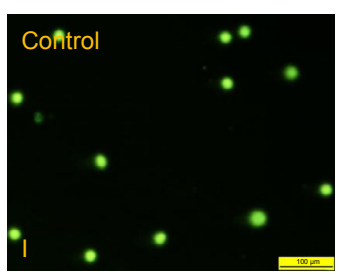

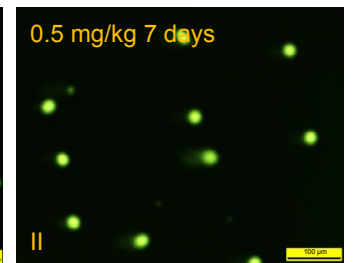

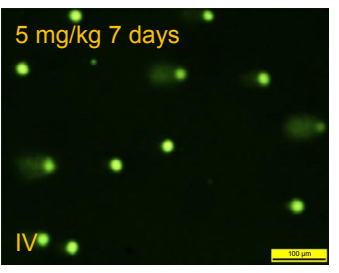

B

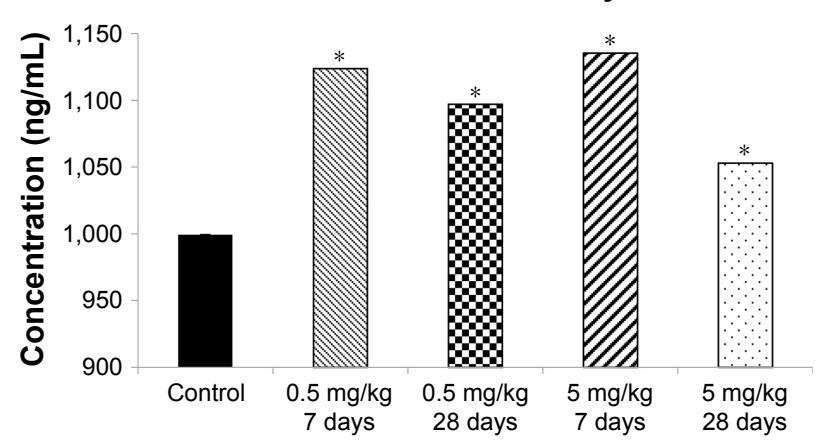

Scoring of comet assay
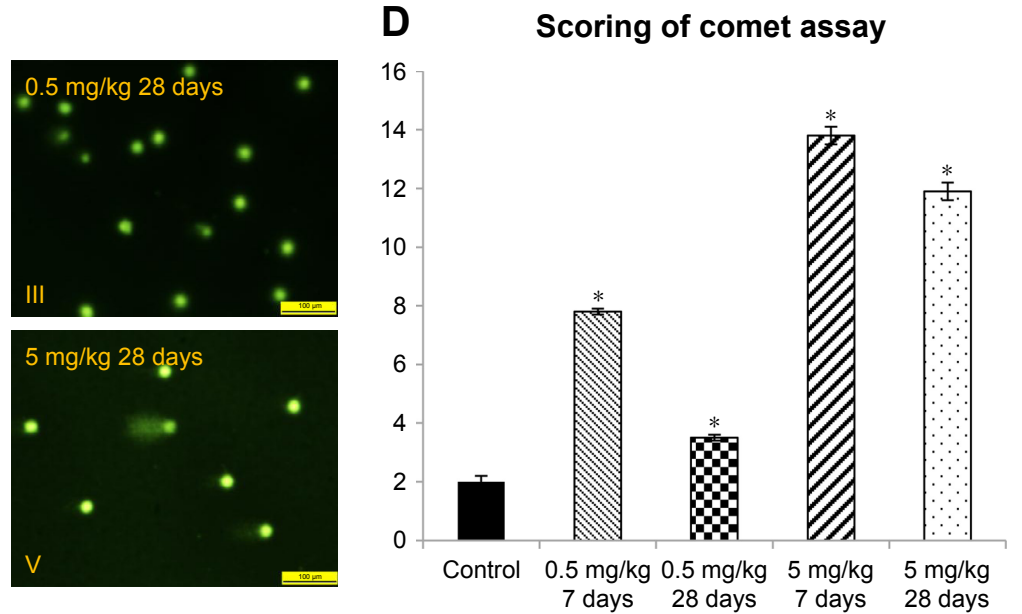

Figure 2 Increased oxidative stress in cAgNP-treated rabbit liver tissue.

Notes: In the malondialdehyde (MDA) assay (A) and the 4-hydroxynonenal (4-HNE) assay (B), levels of oxidative stress markers were increased significantly, and the levels were not recovered after 28 days of cAgNPs treatment. (C) The oxidative DNA damage was increased in cAgNP-treated liver tissue. The high dose (5 mg/kg) resulted in more DNA damage than the low dose $(0.5 \mathrm{mg} / \mathrm{kg})$ in the comet assay analysis. (D) Statistical analysis showed that the DNA damage at the high dose was repaired slightly after 28 days. The scale bar is $100 \mu \mathrm{m}$. The asterisk indicates a significant difference compared to the control group $(P$-value $<0.05)$.

Abbreviation: $\mathrm{CAgNP}$, citrate-coated silver nanoparticle.

connectivity, to identify major associations. Results of the network analysis indicated reliable correlations. Meticulous curation of pathways revealed major networks of genes related to the persistent toxicity of cAgNPs (Figure 5). There were eight upregulated and five downregulated genes, considering key elements in the cAgNP toxicity pathway. Quantitative RT-PCR validation identified serpin family E member 1 (SERPINE1), cyclin-dependent kinase 1 (CDK1), von Willebrand factor $(V W F)$, Adenosine A3 Receptor (ADORA3), and G0/G1 switch 2 (GOS2) consistent with the results of the microarray analysis (Figure 6). These data provide important evidence for the discovery of molecular biomarkers to assess $\mathrm{cAgNP}$ exposure risk.

\section{Discussion}

The widespread use of AgNPs in industrial and household applications has raised concern regarding their safety. Although various studies have demonstrated the risk of AgNP toxicity upon human exposure, the evidence remains unclear due to variability in the studies including those in particle size, shape, and dispersion medium. ${ }^{3,6,14,36} \mathrm{~A}$ recent study showed synergistic toxicity of AgNPs in terms of oxidative stress under coexistence condition with silver ion in Escherichia coli. ${ }^{37}$ Some studies have reported that the shape of surfactant-coated AgNPs could affect the level of toxicity in bacteria or invertebrates; $;^{38-40}$ however, there is insufficient molecular studies of true toxicity of AgNPs in mammalian. AgNP toxicity might depend on stabilizer. In present study, AgNPs were coated with the most common stabilizer, citrate, and the cAgNP size was estimated to be $7.9 \pm 0.95 \mathrm{~nm}$ in our previous study. ${ }^{29}$ In particular, our research focused on dose- and time-dependent alterations in cAgNP-induced toxicity after a single injection of the particles and the transcriptional changes due to retained AgNPs at 28 days after the injection.

Though the toxicity of AgNPs is still unclear, increasing evidence does indicate a human safety concern. ${ }^{14,41}$ Coated AgNPs can enter the systemic circulation through damaged 
skin or other pathways, subsequently being distributed to other organs including liver, kidney, and brain. ${ }^{3,36,42}$ The absorbed AgNPs are likely to pass through liver tissue first, resulting in liver accumulation. ${ }^{4,43}$ Two different studies on AgNP toxicity using a rat model but different routes of exposure (intravenous injection or inhalation) showed contrasting results; one study reported that treatment with AgNPs induced clinical markers of liver damage, ${ }^{41}$ whereas the other study reported no adverse toxicological effects. ${ }^{44}$ In our previous study, serum concentration of silver, histopathological damage, and inflammatory response in liver tissue were found to be higher compared with other tissue parameters. ${ }^{29}$ To clarify the toxic effects on liver tissue in depth, the present study investigated in vivo toxicity of stabilized cAgNPs using rabbit liver tissue by conducting several toxicity tests and transcriptomic analyses.

NP deposition in liver tissue is followed by the penetration of the particles into the cells and altered enzyme activity ${ }^{45}$ and may cause changes in enzymatic composition. ${ }^{46}$ In the present study, we evaluated toxicity on liver tissue after cAgNP exposure by detecting enzymatic markers of liver function and level of apoptosis. Significant changes in both ALP and LDH levels after cAgNP treatment were evident (Figure 1). LDH and ALP are indicators of hepatocellular damage, with increased levels indicating liver damage. ${ }^{46}$ The results of the TUNEL assay revealed increased apoptosis after cAgNP injection. cAgNPs induced liver tissue damage up to 28 days after exposure. These data reveal that cAgNPs can provoke continued and prolonged damage of liver tissue structure and function after a single exposure to the particles.

NPs induce oxidative stress by generating ROS, suggesting a common mechanism for cytotoxicity and genotoxicity. ${ }^{36,47,48}$ Highly reactive ROS are generated by accumulated NPs in mitochondria and lysosomes, leading to major structural damage to proteins and DNA.44,48,49 Our observations led us to check the oxidative stress level of lipid peroxidation in rabbit liver tissue in response to cAgNP

\section{A}
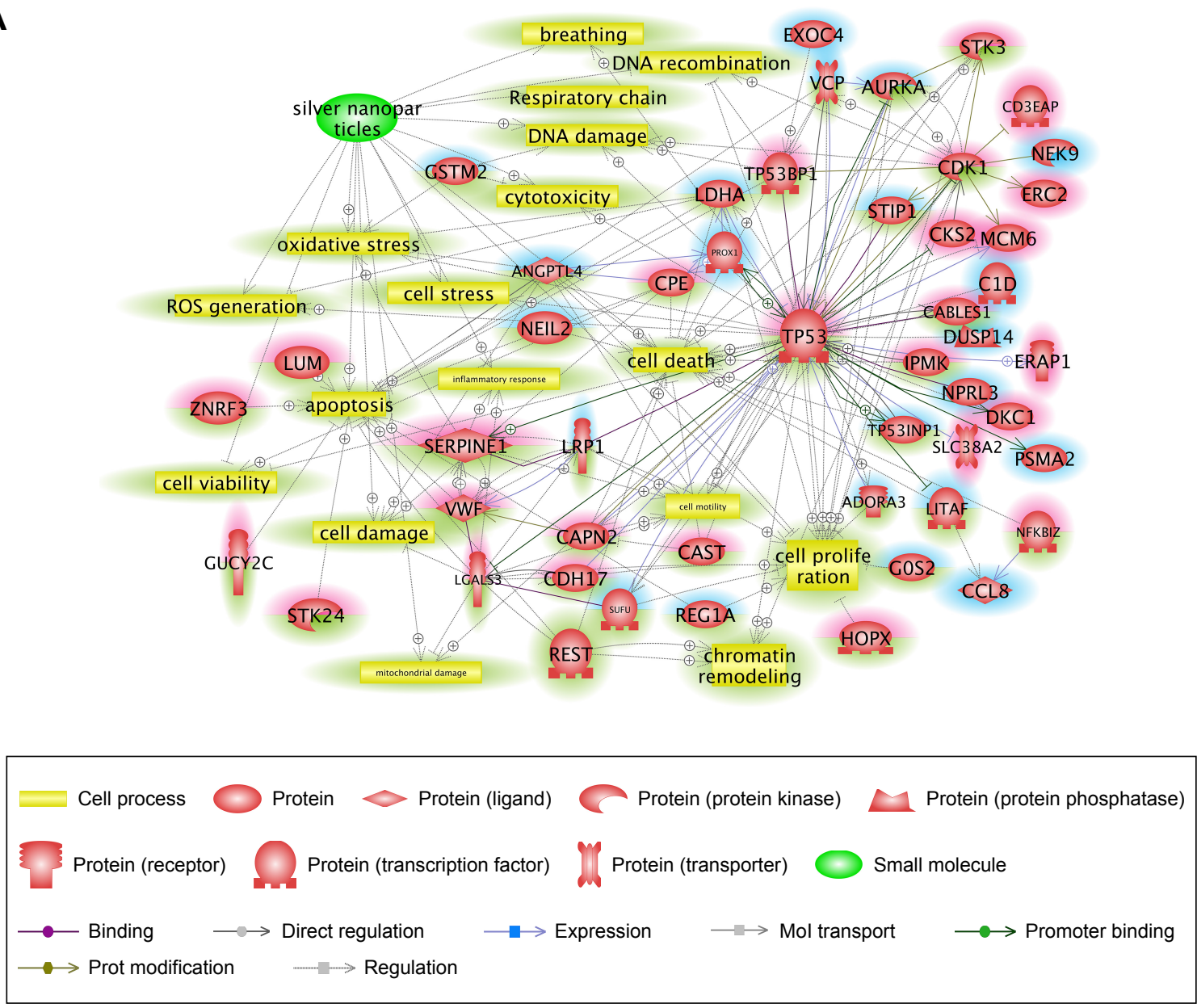

Figure 3 (Continued) 


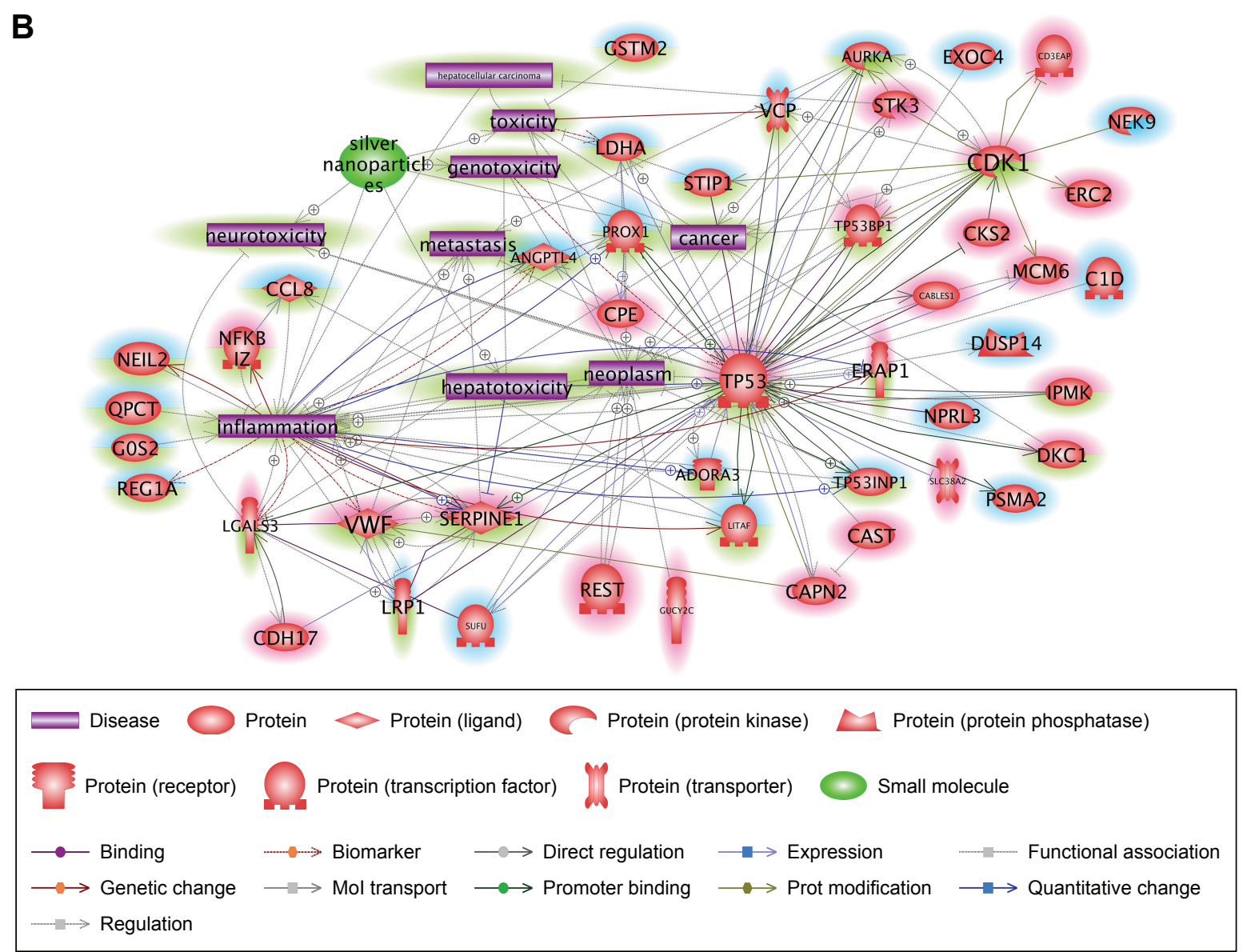

Figure 3 Signaling pathways associated with specifically regulated genes 28 days after cAgNP exposure.

Notes: Pathway Studio was used to explore the interactions among differentially expressed genes. (A) Cell process-related pathways with the genes identified 28 days after exposure were analyzed in the context of AgNPs. (B) Disease-related pathways with the genes are indicated in a purple box. Up- and downregulated genes 28 days after cAgNP exposure are highlighted in red and blue, respectively. The green highlight indicates AgNP-associated cell processes, diseases, or related genes.

Abbreviation: $\mathrm{CAgNP}$, citrate-coated silver nanoparticle.

exposure (Figure $2 \mathrm{~A}$ and $\mathrm{B}$ ). The results supported previous observations that a high dose of cAgNPs might result in higher amounts of MDA and 4-HNE, which slightly decrease over time. Detecting these end-products of lipid peroxidation is a very reliable assay of oxidative damage, and they are also accepted as oxidative stress markers. Moreover, intracellular ROS production results in DNA damage, lipid peroxidation, and protein oxidation, ${ }^{50}$ which leads to cellular component damage to tissues. Likewise, our results showed that a high dose of cAgNPs produced more DNA strand breaks than a low dose. Interestingly, recovery from DNA damage after 28 days was unclear in the high-dose treated groups, with a similar pattern in the MDA level. The in vivo comet assay results revealed that oxidative stress is a major mechanism for cAgNP-mediated toxicity in rabbit liver tissue, suggesting continuous genomic instability due to a single cAgNP exposure that persists (28 days in this study). Indeed, a wealth of evidence indicates that accumulation of DNA damage leads to loss of genomic integrity, which can induce carcinogenesis. Thus, DNA damage is considered as an initial hallmark of cancer. ${ }^{51-53}$ It is conceivable that the consequences of cAgNP toxicity include increased risk of cancer.

Results of transcriptomic analysis in the assessment of toxicogenomic responses can help explain molecular mechanisms and signaling pathways and help discover toxicant-related biomarkers valuable in chemical risk assessment. ${ }^{54}$ To date, there have been only a few gene expression studies implicating AgNPs as a toxic substance in mammalian cell lines or animal models including mouse, rat, and daphnia. ${ }^{55,56}$ The present findings reveal that cAgNPinduced damages can persist. The gene expression profile was explored using cDNA microarray to investigate the toxic effects of AgNPs 28 days after a single injection of $5 \mu \mathrm{g} / \mathrm{mL}$ AgNPs. A total of 244 genes were differentially 


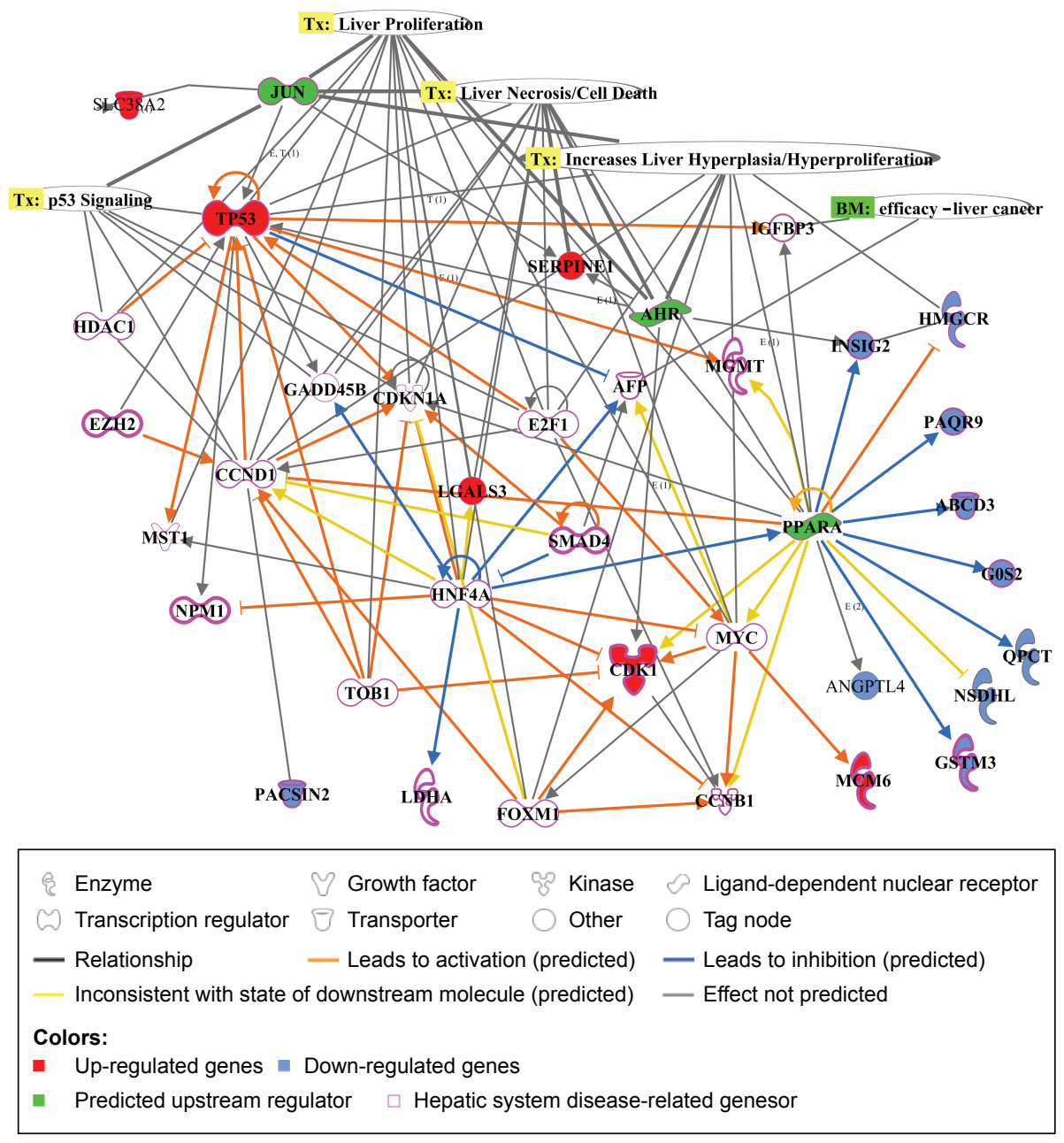

Figure 4 Molecular relationships among the cAgNP-affected genes 28 days after exposure.

Notes: Ingenuity Pathway Analysis was used for understanding the biological interactions between up- and downregulated genes induced 28 days after cAgNP exposure (highlighted in red and blue, respectively). The green highlight represents the upstream regulators predicted by Ingenuity Pathway Analysis. The pink-bordered elements are related to hepatic system diseases.

Abbreviation: cAgNP, citrate-coated silver nanoparticle.

expressed with biological significance (fold change $>1.5$ and $P$-value $<0.05)$. Knowledge-based network analysis using Pathway Studio and Ingenuity Pathway analysis tools revealed that similar to the toxicity test results, genes involved in cell death, apoptosis, and oxidative stress were affected by the presence of cAgNPs. In disease-related pathway analysis, the genes identified were involved in inflammation, toxicity, and cancer. These data are consistent with other reports and indicate potential responses involving differentially expressed genes at different time periods after $\mathrm{cAgNP}$ exposure.

However, the analyzed pathways were too complicated to identify specific important genes among the cAgNP-responsive genes. Accordingly, the pathways were carefully curated with various considerations including the number of references, connectivity with other data, and association with liver tissue. Major networks were sorted and key proteins were identified as potential biomarker candidates of cAgNP toxicity. After validation, CDK1, SERPINE1, VWF, ADORA3, and G0S2 were determined as key proteins. G0S2 also has a protective function as a proapoptotic factor in human cancer cells,${ }^{57}$ although it is known to be a master regulator of lipolysis in adipose and liver tissues ${ }^{58,59}$ ADORA3 is one of the G-protein-coupled receptors with a crucial role in intracellular signaling pathways.$^{60}$ Various studies have demonstrated its protective role in inflammation-related diseases ${ }^{61,62}$ and that downregulation of ADORA3 induces abnormal signal transduction causing tissue damage. Also, SERPINE1 (also known as plasminogen activator inhibitor-1) and $V W F$, which were upregulated in 


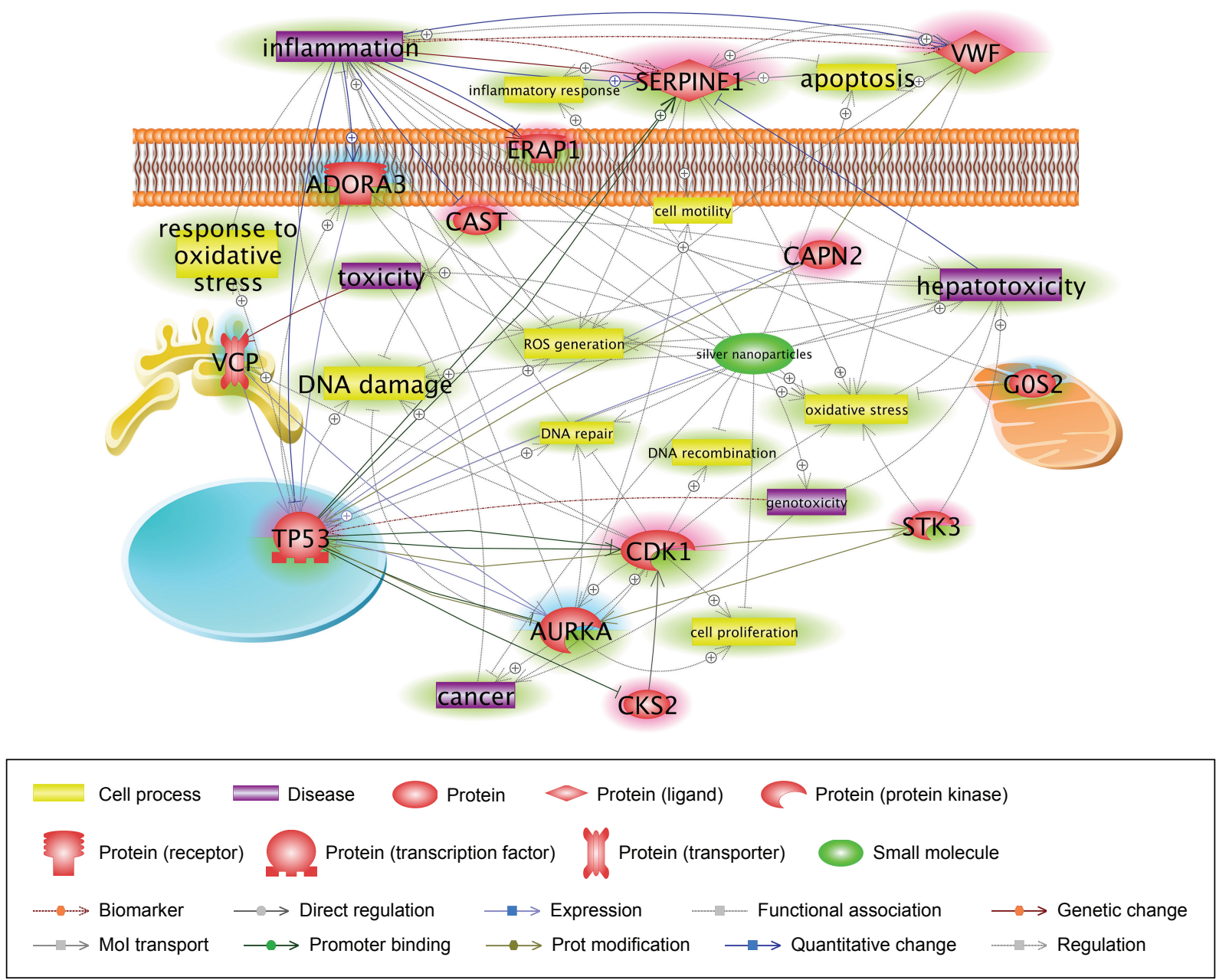

Figure 5 Core networks of significantly AgNP-associated genes.

Notes: The simplified pathway shows major associations among the genes related to the toxicity of retained cAgNPs and was carefully curated based on the number of references and connectivity. The pathway is derived from previous complex interactions analyzed by Pathway Studio or Ingenuity Pathway Analysis. Red and blue highlights indicate up- and downregulated genes, respectively. The green highlight indicates AgNP-associated cell processes, diseases, or related genes.

Abbreviation: $c A g N P$, citrate-coated silver nanoparticle.

the presence of cAgNPs, have been reported as diagnostic biomarkers of inflammation, ${ }^{63}$ and both genes induce oxidative stress under toxic conditions. ${ }^{64,65}$ Indeed, the correlation between AgNPs and the induction of inflammation and oxidative stress was reported in a human liver cell line. ${ }^{66} \mathrm{CDK} 1$ has a recognized role in cell cycle checkpoints at the G1/S and $\mathrm{G} 2 / \mathrm{M}$ phase transitions ${ }^{67}$ It was upregulated by $\mathrm{cAgNP}$ treatment. Interestingly, its overexpression is strongly associated with carcinogenesis. ${ }^{68,69}$ The present data from toxicity tests also suggest the potential carcinogenicity of cAgNPs in terms of continuous genomic instability. Our results suggest that induced gene expression up to 28 days after a single injection of cAgNPs leads to toxic dysfunction of liver tissue. These genes could be considered as potential biomarkers for assessing the toxicity of accumulated cAgNPs.
Our results showed that cAgNPs were toxic to rabbit liver. Rabbit is a proven toxicity model for several human conditions. To our knowledge, no previous information regarding cAgNP-induced genotoxicity or its carcinogenic risk in a rabbit model has been reported. We chose liver as the target organ because of its central role in metabolism and it is vital in the clearance of toxic compounds from the body. We analyzed apoptosis, oxidative stress, and DNA damage, which can be used to assess NP toxicity in vivo. We successfully evaluated cAgNP toxicity in rabbit liver and discovered potential biomarkers for prolonged cAgNP toxicity using microarray analysis, bioinformatics network analysis, and qRT-PCR. Taken together, the results suggest that toxicogenomic analysis in the rabbit in vivo model is suitable for assessing the risks of accumulated AgNPs to 

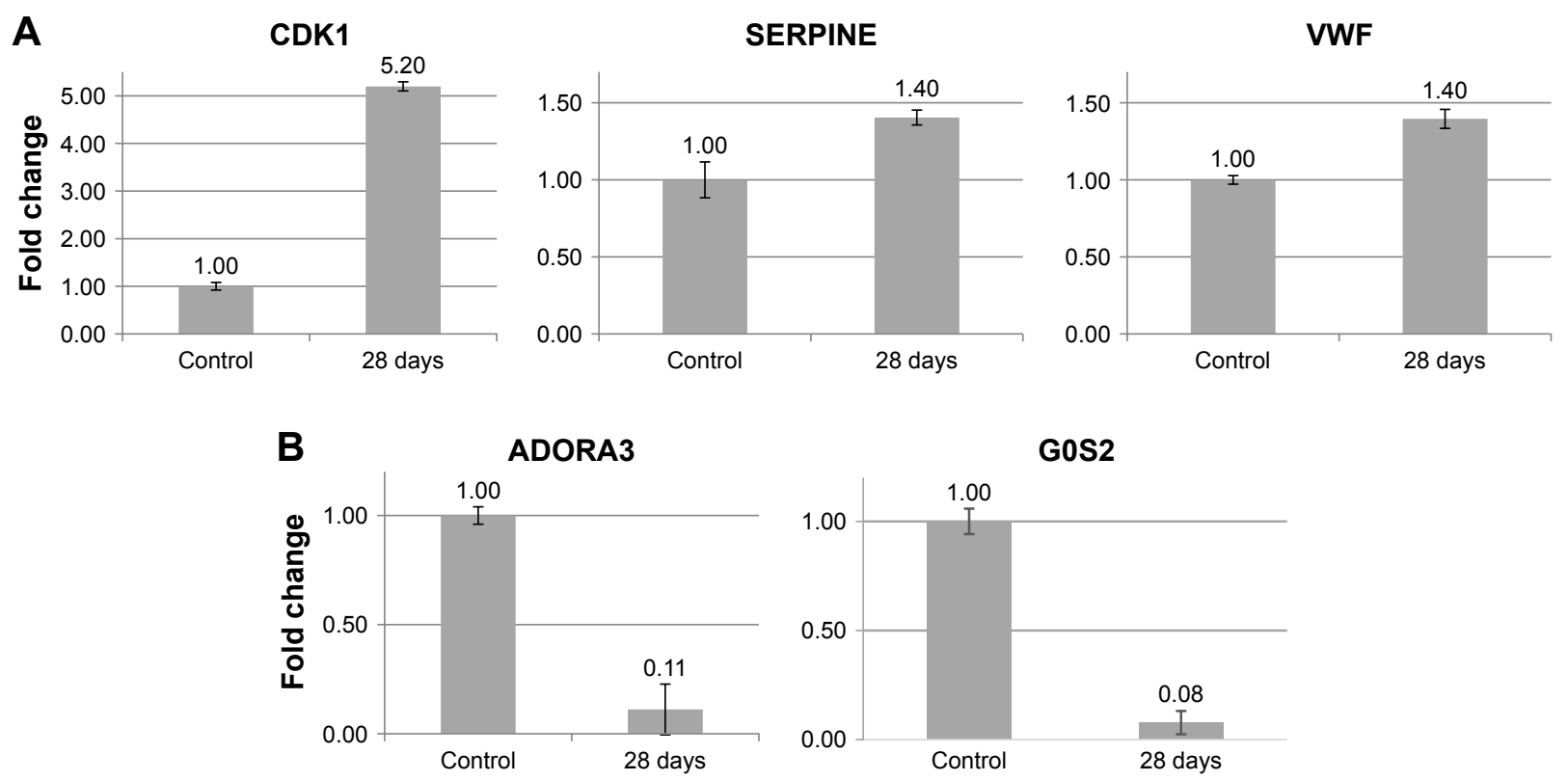

Figure 6 Validation of potential biomarkers of $c A g N P$ exposure in rabbit liver tissue using qRT-PCR.

Notes: (A and B) Illustrate expression of up- and downregulated genes, respectively. Bars indicate the gene expression levels measured using qRT-PCR. The Y-axis denotes the fold-expression change of the respective genes.

Abbreviation: cAgNP, citrate-coated silver nanoparticle.

human health. Furthermore, the present study provides new evidence for understanding prolonged hepatotoxicity of cAgNPs, particularly DNA damage and oxidative stress.

\section{Acknowledgments}

This research was supported by a grant (14CTAPC086804-01) from the Technology Advancement Research Program funded by the Ministry of Land, Infrastructure and Transport of the Korean government. This work was also supported by a grant (NIER-SP2014-053-P10) from the National Institute of Environmental Research (NIER) and by a grant (2016001360009) funded by the Ministry of Environment of the Republic of Korea.

\section{Disclosure}

The authors report no conflicts of interest in this work.

\section{References}

1. Park H-G, Yeo M-K. Nanomaterial regulatory policy for human health and environment. Mol Cell Toxicol. 2016;12(3):223-236.

2. Raj S, Jose S, Sumod US, Sabitha M. Nanotechnology in cosmetics: opportunities and challenges. J Pharm Bioallied Sci. 2012;4(3): 186-193.

3. Skalska J, Dąbrowska-Bouta B, Strużyńska L. Oxidative stress in rat brain but not in liver following oral administration of a low dose of nanoparticulate silver. Food Chem Toxicol. 2016;97:307-315.

4. Arora S, Jain J, Rajwade JM, Paknikar KM. Interactions of silver nanoparticles with primary mouse fibroblasts and liver cells. Toxicol Appl Pharmacol. 2009;236(3):310-318.
5. Pelletier DA, Suresh AK, Holton GA, et al. Effects of engineered cerium oxide nanoparticles on bacterial growth and viability. Appl Environ Microbiol. 2010;76(24):7981-7989.

6. Massarsky A, Trudeau VL, Moon TW. Predicting the environmental impact of nanosilver. Environ Toxicol Pharmacol. 2014;38(3): 861-873.

7. Zhao CM, Wang WX. Biokinetic uptake and efflux of silver nanoparticles in Daphnia magna. Environ Sci Technol. 2010;44(19):7699-7704.

8. Farkas J, Christian P, Urrea JA, et al. Effects of silver and gold nanoparticles on rainbow trout (Oncorhynchus mykiss) hepatocytes. Aquat Toxicol. 2010;96(1):44-52.

9. Gutierrez L, Aubry C, Cornejo M, Croue JP. Citrate-coated silver nanoparticles interactions with effluent organic matter: influence of capping agent and solution conditions. Langmuir. 2015;31(32):8865-8872.

10. Sharma VK, Yngard RA, Lin Y. Silver nanoparticles: green synthesis and their antimicrobial activities. Adv Colloid Interface Sci. 2009; 145(1-2):83-96.

11. Bastos V, Duarte IF, Santos C, Oliveira H. Genotoxicity of citrate-coated silver nanoparticles to human keratinocytes assessed by the comet assay and cytokinesis blocked micronucleus assay. Environ Sci Pollut Res Int. 2017;24(5):5039-5048.

12. Bastos V, Ferreira-de-Oliveira JMP, Carrola J, et al. Coating independent cytotoxicity of citrate- and PEG-coated silver nanoparticles on a human hepatoma cell line. J Environ Sci. 2017;51:191-201.

13. Gliga AR, Skoglund S, Wallinder IO, Fadeel B, Karlsson HL. Sizedependent cytotoxicity of silver nanoparticles in human lung cells: the role of cellular uptake, agglomeration and Ag release. Part Fibre Toxicol. 2014;11:11.

14. Kim JS, Song KS, Sung JH, et al. Genotoxicity, acute oral and dermal toxicity, eye and dermal irritation and corrosion and skin sensitisation evaluation of silver nanoparticles. Nanotoxicology. 2013;7(5):953-960.

15. Genter MB, Newman NC, Shertzer HG, Ali SF, Bolon B. Distribution and systemic effects of intranasally administered $25 \mathrm{~nm}$ silver nanoparticles in adult mice. Toxicol Pathol. 2012;40(7):1004-1013.

16. Park K, Park EJ, Chun IK, et al. Bioavailability and toxicokinetics of citrate-coated silver nanoparticles in rats. Arch Pharm Res. 2011;34(1): $153-158$. 
17. Kim YS, Song MY, Park JD, et al. Subchronic oral toxicity of silver nanoparticles. Part Fibre Toxicol. 2010;7:20.

18. Sung JH, Ji JH, Park JD, et al. Subchronic inhalation toxicity of silver nanoparticles. Toxicol Sci. 2009;108(2):452-461.

19. Ebabe Elle R, Gaillet S, Vidé J, et al. Dietary exposure to silver nanoparticles in Sprague-Dawley rats: effects on oxidative stress and inflammation. Food Chem Toxicol. 2013;60:297-301.

20. El Mahdy MM, Eldin TA, Aly HS, Mohammed FF, Shaalan MI. Evaluation of hepatotoxic and genotoxic potential of silver nanoparticles in albino rats. Exp Toxicol Pathol. 2015;67(1):21-29.

21. Heydrnejad MS, Samani RJ, Aghaeivanda S. Toxic effects of silver nanoparticles on liver and some hematological parameters in male and female mice (Mus musculus). Biol Trace Elem Res. 2015;165(2): $153-158$.

22. Dong MS, Choi JY, Sung JH, et al. Gene expression profiling of kidneys from Sprague-Dawley rats following 12-week inhalation exposure to silver nanoparticles. Toxicol Mech Methods. 2013;23(6): $437-448$.

23. Gao X, Topping VD, Keltner Z, Sprando RL, Yourick JJ. Toxicity of nano- and ionic silver to embryonic stem cells: a comparative toxicogenomic study. J Nanobiotechnology. 2017;15(1):31.

24. Yr A, Kim JY, Kim YS. Construction of a predictive model for evaluating multiple organ toxicity. Mol Cell Toxicol. 2016;12(1):1-6.

25. Koedrith P, Kim H, Weon JI, Seo YR. Toxicogenomic approaches for understanding molecular mechanisms of heavy metal mutagenicity and carcinogenicity. Int J Hyg Environ Health. 2013;216(5):587-598.

26. Shin WC, Eun JW, Shen Q, et al. Identification of aberrant overexpression of long non-coding RNA MALAT1 and role as a regulatory microRNA in liver cancer. Mol Cell Toxicol. 2017;13(4):443-451.

27. Gagné F, André C, Skirrow R, et al. Toxicity of silver nanoparticles to rainbow trout: a toxicogenomic approach. Chemosphere. 2012;89(5): 615-622.

28. Fabro S, Smith RL. The teratogenic activity of thalidomide in the rabbit. J Pathol Bacteriol. 1966;91(2):511-519.

29. Lee Y, Kim P, Yoon J, et al. Serum kinetics, distribution and excretion of silver in rabbits following 28 days after a single intravenous injection of silver nanoparticles. Nanotoxicology. 2013;7(6):1120-1130.

30. Kim HL, Seo YR. Molecular and genomic approach for understanding the gene-environment interaction between $\mathrm{Nrf} 2$ deficiency and carcinogenic nickel-induced DNA damage. Oncol Rep. 2012;28(6): 1959-1967.

31. Nikitin A, Egorov S, Daraselia N, Mazo I. Pathway studio - the analysis and navigation of molecular networks. Bioinformatics. 2003;19(16): 2155-2157.

32. Krämer A, Green J, Pollard J, Tugendreich S. Causal analysis approaches in Ingenuity Pathway Analysis. Bioinformatics. 2014;30(4): 523-530.

33. Ramaiah SK. A toxicologist guide to the diagnostic interpretation of hepatic biochemical parameters. Food Chem Toxicol. 2007;45(9): $1551-1557$

34. Yu Y, Liao M, Liu R, Chen J, Feng H, Fu Z. Overexpression of lactate dehydrogenase-A in human intrahepatic cholangiocarcinoma: its implication for treatment. World J Surg Oncol. 2014;12:78.

35. Kim DH, Kwack SJ, Yoon KS, Choi JS, Lee BM. 4-Hydroxynonenal: a superior oxidative biomarker compared to malondialdehyde and carbonyl content induced by carbon tetrachloride in rats. $J$ Toxicol Environ Health A. 2015;78(16):1051-1062.

36. Vrček IV, Žuntar I, Petlevski R, et al. Comparison of in vitro toxicity of silver ions and silver nanoparticles on human hepatoma cells. Environ Toxicol. 2016;31(6):679-692.

37. Choi Y, Kim HA, Kim KW, Lee BT. Comparative toxicity of silver nanoparticles and silver ions to Escherichia coli. J Environ Sci. 2018; 66:50-60.

38. Chakraborty I, Feliu N, Roy S, Dawson K, Parak WJ. Protein-mediated shape control of silver nanoparticles. Bioconjug Chem. 2018;29(4): 1261-1265.
39. Tejamaya M, Römer I, Merrifield RC, Lead JR. Stability of citrate, PVP, and PEG coated silver nanoparticles in ecotoxicology media. Environ Sci Technol. 2012;46(13):7011-7017.

40. El Badawy AM, Silva RG, Morris B, Scheckel KG, Suidan MT, Tolaymat TM. Surface charge-dependent toxicity of silver nanoparticles. Environ Sci Technol. 2011;45(1):283-287.

41. Cassel CK, Meier DE. Morals and moralism in the debate over euthanasia and assisted suicide. $N$ Engl J Med. 1990;323(11):750-752.

42. Walker M, Parsons D. The biological fate of silver ions following the use of silver-containing wound care products - a review. Int Wound $J$. 2014;11(5):496-504.

43. Takenaka S, Karg E, Roth C, et al. Pulmonary and systemic distribution of inhaled ultrafine silver particles in rats. Environ Health Perspect. 2001;109(Suppl 4):547-551.

44. Hyun JS, Lee BS, Ryu HY, Sung JH, Chung KH, Yu IJ, Ij Y. Effects of repeated silver nanoparticles exposure on the histological structure and mucins of nasal respiratory mucosa in rats. Toxicol Lett. 2008; 182(1-3):24-28.

45. Kim S, Choi JE, Choi J, et al. Oxidative stress-dependent toxicity of silver nanoparticles in human hepatoma cells. Toxicol In Vitro. 2009; 23(6):1076-1084.

46. Tiwari DK, Jin T, Behari J. Dose-dependent in-vivo toxicity assessment of silver nanoparticle in Wistar rats. Toxicol Mech Methods. 2011; 21(1):13-24.

47. M-R J, Chung H-E, Kim H-J, et al. Effects of zinc oxide nanoparticle dispersants on cytotoxicity and cellular uptake. Mol Cell Toxicol. 2016;12(3):281-288.

48. Wei L, Lu J, Xu H, Patel A, Chen ZS, Chen G. Silver nanoparticles: synthesis, properties, and therapeutic applications. Drug Discov Today. 2015;20(5):595-601.

49. Wang E, Huang Y, du Q, Sun Y. Silver nanoparticle induced toxicity to human sperm by increasing ROS (reactive oxygen species) production and DNA damage. Environ Toxicol Pharmacol. 2017;52:193-199.

50. Piao MJ, Kang KA, Lee IK, et al. Silver nanoparticles induce oxidative cell damage in human liver cells through inhibition of reduced glutathione and induction of mitochondria-involved apoptosis. Toxicol Lett. 2011;201(1):92-100.

51. Kang SH, Kwon JY, Lee JK, Seo YR. Recent advances in in vivo genotoxicity testing: prediction of carcinogenic potential using comet and micronucleus assay in animal models. J Cancer Prev. 2013;18(4): 277-288.

52. O'Connor MJ. Targeting the DNA damage response in cancer. Mol Cell. 2015;60(4):547-560.

53. Wang H, Zhang X, Teng L, Legerski RJ. DNA damage checkpoint recovery and cancer development. Exp Cell Res. 2015;334(2):350-358.

54. Li HH, Hyduke DR, Chen R, et al. Development of a toxicogenomics signature for genotoxicity using a dose-optimization and informatics strategy in human cells. Environ Mol Mutagen. 2015;56(6):505-519.

55. Huang CL, Hsiao IL, Lin HC, Wang CF, Huang YJ, Chuang CY. Silver nanoparticles affect on gene expression of inflammatory and neurodegenerative responses in mouse brain neural cells. Environ Res. 2015;136:253-263.

56. Mcquillan JS, Shaw AM. Differential gene regulation in the Ag nanoparticle and $\mathrm{Ag}(+)$-induced silver stress response in Escherichia coli: a full transcriptomic profile. Nanotoxicology. 2014;8(Suppl 1):177-184.

57. Yamada T, Park CS, Shen Y, Rabin KR, Lacorazza HD. G0S2 inhibits the proliferation of K562 cells by interacting with nucleolin in the cytosol. Leuk Res. 2014;38(2):210-217.

58. Sun J, Yang Z, Shi XC, Ji H, du ZY, Chen LQ. G0S2a1 (G0/G1 switch gene 2a1) is downregulated by TNF- $\alpha$ in grass carp (Ctenopharyngodon idellus) hepatocytes through PPAR $\alpha$ inhibition. Gene. 2018;641:1-7.

59. Wang Y, Zhang Y, Qian $\mathrm{H}$, et al. The $\mathrm{g} 0 / \mathrm{g} 1$ switch gene 2 is an important regulator of hepatic triglyceride metabolism. PLoS One. 2013; 8(8):e72315.

60. Poulsen SA, Quinn RJ. Adenosine receptors: new opportunities for future drugs. Bioorg Med Chem. 1998;6(6):619-641. 
61. Bar-Yehuda S, Silverman MH, Kerns WD, Ochaion A, Cohen S, Fishman P. The anti-inflammatory effect of A3 adenosine receptor agonists: a novel targeted therapy for rheumatoid arthritis. Expert Opin Investig Drugs. 2007;16(10):1601-1613.

62. Ren T, Qiu Y, Wu W, et al. Activation of adenosine A3 receptor alleviates TNF- $\alpha$-induced inflammation through inhibition of the NF- $\kappa B$ signaling pathway in human colonic epithelial cells. Mediators Inflamm. Epub 2014 Apr 22.

63. Kawecki C, Lenting PJ, Denis CV. von Willebrand factor and inflammation. J Thromb Haemost. 2017;15(7):1285-1294.

64. Agostini S, Lionetti V. New insights into the non-hemostatic role of von Willebrand factor in endothelial protection. Can J Physiol Pharmacol. 2017;95(10):1183-1189.

65. Oggianu L, Lancellotti S, Pitocco D, et al. The oxidative modification of von Willebrand factor is associated with thrombotic angiopathies in diabetes mellitus. PLoS One. 2013;8(1):e55396.
66. Braakhuis HM, Gosens I, Krystek P, et al. Particle size dependent deposition and pulmonary inflammation after short-term inhalation of silver nanoparticles. Part Fibre Toxicol. 2014;11:49.

67. Brown NR, Korolchuk S, Martin MP, et al. CDK1 structures reveal conserved and unique features of the essential cell cycle CDK. Nat Commun. 2015;6:6769.

68. Yang W, Cho H, Shin HY, et al. Accumulation of cytoplasmic Cdk1 is associated with cancer growth and survival rate in epithelial ovarian cancer. Oncotarget. 2016;7(31):49481-49497.

69. Zhao J, Han SX, Ma JL, J1 M, et al. The role of CDK1 in apoptin-induced apoptosis in hepatocellular carcinoma cells. Oncol Rep. 2013;30(1) $253-259$.
International Journal of Nanomedicine

\section{Publish your work in this journal}

The International Journal of Nanomedicine is an international, peerreviewed journal focusing on the application of nanotechnology in diagnostics, therapeutics, and drug delivery systems throughout the biomedical field. This journal is indexed on PubMed Central, MedLine, CAS, SciSearch $®$, Current Contents $\AA /$ Clinical Medicine,

\section{Dovepress}

Journal Citation Reports/Science Edition, EMBase, Scopus and the Elsevier Bibliographic databases. The manuscript management system is completely online and includes a very quick and fair peer-review system, which is all easy to use. Visit http://www.dovepress.com/ testimonials.php to read real quotes from published authors.

Submit your manuscript here: http://www.dovepress.com/international-journal-of-nanomedicine-journal 